Article

\title{
Photophysical and Electroluminescence Characteristics of Polyfluorene Derivatives with Triphenylamine
}

\author{
Qiang Zhang ${ }^{1}$, Po-I. Wang ${ }^{1}{ }^{(0)}$, Guang Liang Ong ${ }^{2}{ }^{\circledR}$, Shen Hoong Tan ${ }^{2}$, Zhong Wei Tan ${ }^{2}$, \\ Yew Han Hii ${ }^{2}$, Yee Lin Wong ${ }^{2}$, Khee Sang Cheah ${ }^{2} \mathbb{D}$, Seong Ling Yap ${ }^{3}$, Teng Sian Ong ${ }^{2} \mathbb{D}$, \\ Teck Yong Tou ${ }^{2}$, Chen Hon Nee ${ }^{2, *(D)}$, Der Jang Liaw ${ }^{1, *}$ and Seong Shan Yap ${ }^{2}$ (D) \\ 1 Department of Chemical Engineering, National Taiwan University of Science and Technology, Taipei 10607, \\ Taiwan; zhangyunyiyi@gmail.com (Q.Z.); wangpoi.ntust@gmail.com (P.-I.W.) \\ 2 Faculty of Engineering, Multimedia University, Persiaran Multimedia, Cyberjaya 63100, Malaysia; \\ ogeeal@gmail.com (G.L.O.); shenhoong5059@gmail.com (S.H.T.); zacktan93@hotmail.com (Z.W.T.); \\ joshuahiiyewhan@gmail.com (Y.H.H.); yeelin823@gmail.com (Y.L.W.); kheesang@gmail.com (K.S.C.); \\ seantso90@gmail.com (T.S.O.); tytou_mmu@yahoo.com (T.Y.T.); seongshan@gmail.com (S.S.Y.) \\ 3 Department of Physics, University of Malaya, Lembah Pantai, Kuala Lumpur 50603, Malaysia; \\ slyap@um.edu.my \\ * Correspondence: neechenhon@gmail.com (C.H.N.); liawdj@gmail.com (D.J.L.)
}

Received: 7 March 2019; Accepted: 30 March 2019; Published: 9 May 2019

\begin{abstract}
In this work, polymers of poly[(9,9-dioctylfluorenyl-2,7-diyl)-co-triphenylamine] with side chains containing: pyrene (C1), diphenyl (C2), naphthalene (C3), and isopropyl (C6) structures were synthesized via a Suzuki coupling reaction. The structures were verified using NMR and cyclic voltammetry measurements provide the HOMO and LUMO of the polymers. The polymer with pyrene (C1) and naphthalene (C3) produced photoluminescence in the green while the polymer with the side chain containing diphenyl (C2) and isopropyl (C6) produce dual emission peaks of blue-green photoluminescence (PL). In order to examine the electroluminescence properties of the polymers, the solutions were spin-coated onto patterned ITO anode, dried, and subsequently coated with an Al cathode layer to form pristine single layer polymer LEDs. The results are compared to a standard PFO sample. The electroluminescence spectra resemble the PL spectra for C1 and C3. The devices of C2, C3, and C6 exhibit voltage-dependent EL. An additional red emission peak was detected for C2 and C6, resulting in spectra with peaks at $435 \mathrm{~nm}, 490 \mathrm{~nm}$, and $625 \mathrm{~nm}$. The effects of the side chains on the spectral characteristics of the polymer are discussed.
\end{abstract}

Keywords: semiconducting polymer; electroluminescence; polyfluorene; triphenylamine; PLED; Suzuki coupling; OLED

\section{Introduction}

Conjugated polymers are attractive because of the combined advantage of flexibility and conductivity for electronics and various forthcoming applications [1-6]. Since 1990, electroluminescence (EL) has been observed from a variety of conjugated polymers [7]. It was first shown that multiple emission colors can be obtained using blending polymers with different emission and charge-transport characteristics [8]. Polyfluorene (PF) is one of the promising polymers for both organic solar cell and light emitting diodes because of the large bandgap that enable blue fluorescence [9]. The capability makes polyfluorene the first family that emits in the whole visible spectra, from blue to red [10]. Single emission was typically obtained from each polymer, but the findings infer that multiple emissions may be achieved via modification and proper design of the polymers. The introduction of a copolymer 
or side chain into polyfluorene, for example, further increases the tunability of the emission spectra of the polymer, showing that multicolor emission from a single polymer component is possible [11]. Red-green-blue emission from a single polymer was achieved recently from a star-shaped polymer [12], where PF provided emission in the blue, and modification in the core produced green emission, and finally, the addition of a dopant contributed the red emission. The dopant can consist of metal complexes, dye, or quantum dots that were incorporated into the polymer [11-14]. In order to stabilize the blue emission from PF, triphenylamine (TPA) has been used with PF. A TPA-based polymer also exhibits good hole-transporting properties for organic electronics [15]. PF derivatives bearing TPA have been shown to result in a two-dimensional conjugated system that suppress $\pi$-stacking/aggregation, improves hole injection, and facilitates intramolecular energy transfer in single- and double-layer OLEDs [16]. PF-based copolymers containing TPA in the side chain improve the thermal and morphological stability and act as an antioxidant, thus stabilizing the blue emission from poly(9,9-di-n-octylfluorenyl-2,7-diyl) PFO [17]. The presence of a triphenylamine-based hydrazone comonomer with PF also improved the device performance as compared to those with a PF homopolymer [18].

In this work, we synthesized and investigated the spectral characteristics of four polymers constituting a PFO and TPA backbone of poly[(9,9-dioctylfluorenyl-2,7-diyl)-co-triphenylamine $]$ with side chains containing either: pyrene (C1), diphenyl (C2), naphthalene (C3), or isopropyl (C6). The effects of different side chains on the photophysical and electroluminescence spectral characteristics are compared and discussed. Polymers $\mathrm{C} 1$ and $\mathrm{C} 3$ exhibited rather different emission characteristics as compared to $\mathrm{C} 2$ and $\mathrm{C} 6$ when optically excited. The difference can also be observed when the polymers are fabricated into single layer OLEDs with the structure of ITO/polymer/Al.

\section{Experimental}

\subsection{Polymer Synthesis}

The dibromo monomers of M1, M2, M3, and M6 were synthesized via Buchwald-Hartwig amination as shown in Figure 1. Suzuki coupling polymerization yielded the polymer with M1, M2, M3, and M6 in Figure 2. The synthesis processes are described in the Supplementary Information and in our previous work $[15,19,20]$. The details of $\mathrm{C} 6$ are given in the supplementary data (Figures S1 and S2), while the data for $\mathrm{C} 1, \mathrm{C} 2$, and $\mathrm{C} 3$ are derived from our previous work. The structures were verified using NMR (Figure S3) and cyclic voltammetry measurements (Figure S4) to provide the HOMO and LUMO of the polymers as shown in Table 1.

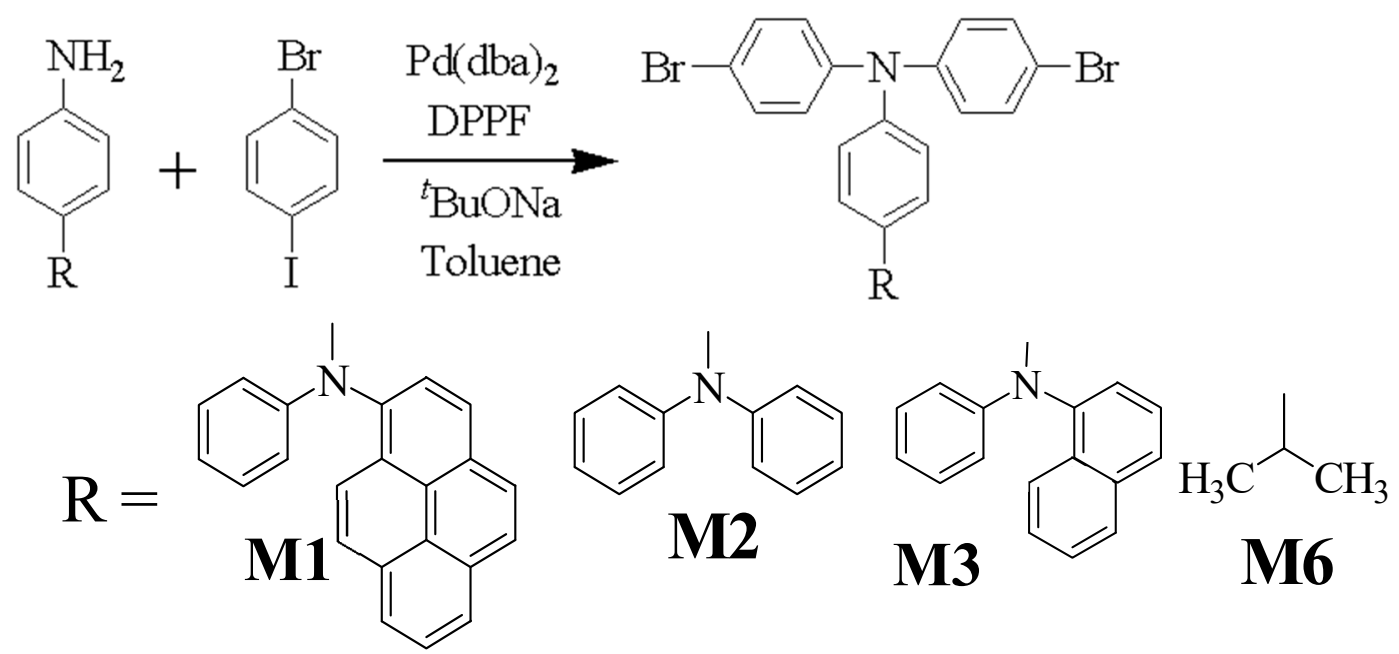

Figure 1. The Buchwald-Hartwig amination process was used to produce M1, M2, M3, and M6. 


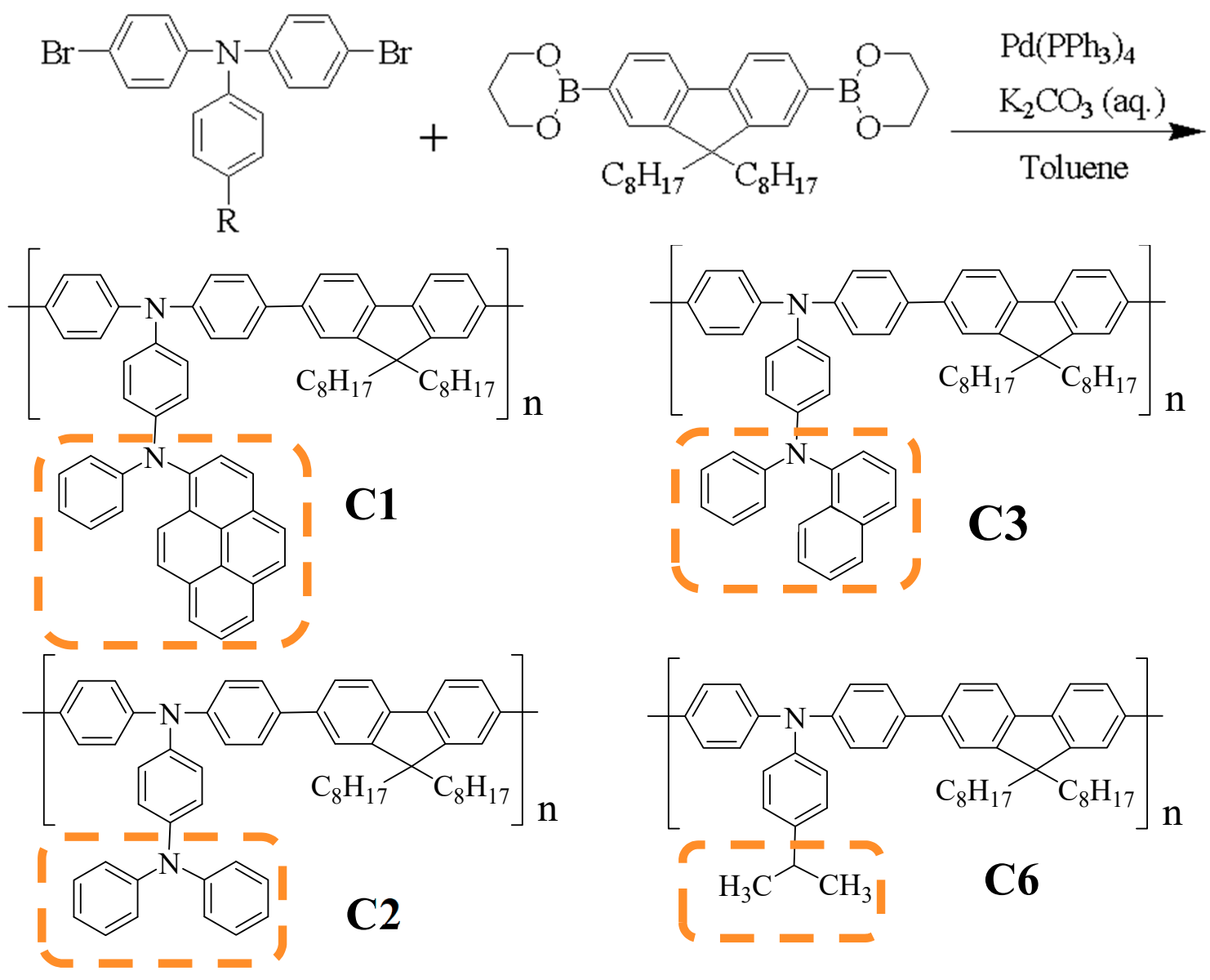

Figure 2. Polymers C1, C2, C3, and C6 are synthesized via the Suzuki coupling method.

Table 1. Electrochemical Properties of the Conjugated Polymers C1, C2, C3, and C6.

\begin{tabular}{cccc}
\hline Polymer & HOMO $^{a}(\mathrm{eV})$ & LUMO $^{a}(\mathrm{eV})$ & $\mathrm{E}_{\mathrm{g}}{ }^{\boldsymbol{b}}(\mathrm{eV})$ \\
\hline $\mathrm{C} 1^{c}$ & -4.96 & -2.20 & 2.76 \\
\hline $\mathrm{C} 2^{c}$ & -5.03 & -2.19 & 2.84 \\
\hline $\mathrm{C} 3^{c}$ & -4.86 & -2.08 & 2.78 \\
\hline $\mathrm{C} 6$ & -5.16 & -2.26 & 2.90
\end{tabular}

${ }^{a}$ Calculated using the equations: $\mathrm{HOMO}=-\left(E_{\text {onset }}^{\mathrm{ox}}-E_{\mathrm{onset}}^{\mathrm{Fc}}\right)-4.8$ and LUMO $=\mathrm{HOMO}+$ band gap. ${ }^{b}$ Calculated from the UV absorption spectrum of the polymer films using the equation: band gap $(\mathrm{eV})=1240 / \lambda_{\text {onset }}^{\text {abs }}{ }^{c}$ Data of C2 derived from our previous work [15], and C1, C3 from references [19,20].

\subsection{OLED Fabrication}

The synthesized polymers in the form of powders were first dissolved in chloroform to obtain different concentrations in a glove box. As a comparison, commercial poly (9,9-di-n-octylfluorenyl2,7-diyl) (PFO) (Ossila, Sheffield, UK) was also used and dissolved in the same solvent. The concentrations of the polymer solution were kept at $5-6 \mathrm{mg} / \mathrm{mL}$, except for $\mathrm{C} 1$, which had a lower solubility, thus a concentration of $2 \mathrm{mg} / \mathrm{mL}$ was used. In order to fabricate OLED devices with the polymers, ITO-coated glass $(2.5 \mathrm{~cm} \times 2.5 \mathrm{~cm})$ with a resistivity of $2 \times 10^{-4} \Omega \cdot \mathrm{cm}$ were etched with $\mathrm{HBr}$ into $2 \mathrm{~mm}$ strips to define the anode. After wet cleaning and UV ozone cleaning for $10 \mathrm{~min}$, polymer solutions were spin-cast onto the ITO substrates at $2000 \mathrm{rpm}$ and annealed at $60^{\circ} \mathrm{C}$ for $30 \mathrm{~min}$. Subsequently, an Al layer with thickness $\approx 100 \mathrm{~nm}$ was deposited by using a thermal evaporator (Edwards Auto 306, Edwards, Burgess Hill, UK) as the cathode. The resultant thicknesses of the polymer layer of $\mathrm{C} 2, \mathrm{C} 3, \mathrm{C} 6$, and $\mathrm{PFO}$ were $\approx 50-80 \mathrm{~nm}$, while $\mathrm{C} 1$ was $\approx 30 \mathrm{~nm}$. The thicknesses of 
layers were measured by using a profilometer (Mahr Perthometer S2, Mahr, Göttingen, Germany). The absorbance (Abs) and photoluminescence (PL) spectra of the polymer films prepared from solution with different concentrations were measured using a UV-vis NIR spectrometer (Avantes, Apeldoorn, The Netherlands), and excited with $368 \mathrm{~nm}$ light to obtain the PL spectra. The single-layer device of ITO/polymer/Al is shown in Figure 3. The I-V characteristics were measured using a source measurement unit (Keithley 236) and the electroluminescence (EL) spectra were captured using a spectrometer (200-1100 nm) (Avantes AvaSpec-2048L, Avantes, Apeldoorn, The Netherlands).

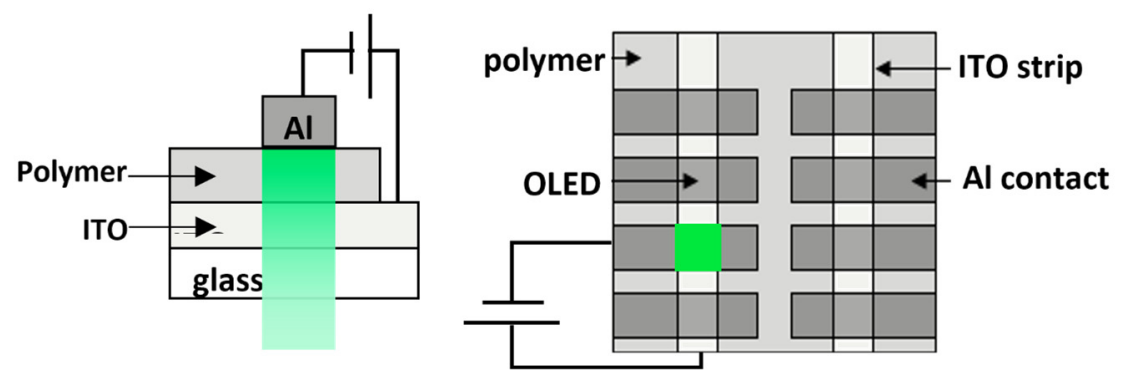

Figure 3. Schematic of the side view and top view of the polymer OLED device structure.

\section{Results and Discussion}

\subsection{Absorption and Photoluminescence Spectra}

The absorption spectra of all the polymer films were compared to the absorption of a commercial PFO sample in Figure 4. All the polymers absorbed from $\approx 300 \mathrm{~nm}$ to $420-450 \mathrm{~nm}$ depending on the polymer samples. The maximum absorption peak for PFO was obtained at $\approx 383 \mathrm{~nm}$ because of the $\pi-\pi^{*}$ transition. When the backbone was modified with TPA in C1, C2, C3, and C6, the absorption peaks were broadened. In addition, the main peak at 380-390 nm was red-shifted for C1 and C3. Additional peaks at 320-348 nm were detected for $\mathrm{C} 1$, where it was reported to be due to the pyrene structure in the side chain [21]. C3 with a naphthalene structure in the side chain had a lower peak at $\approx 310 \mathrm{~nm}$. The maximum absorption peaks of C2 and C6 were close to that of a PFO. Another peak was detected at $\approx 300 \mathrm{~nm}$, which has been reported for the triphenylamine unit in the polymer $[15,22]$. It was clearly distinguishable for C2 and C6 with a less rigid side chain, but was not well resolved for C1 and C3.

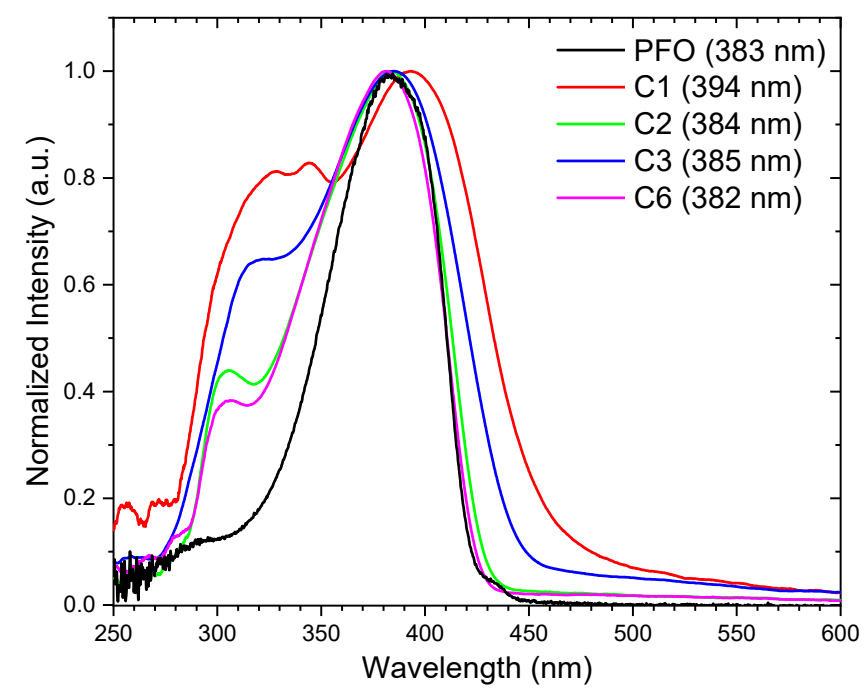

Figure 4. Normalized absorbance of C1, C2, C3, and C6 as compared to a PFO film (black). The maximum absorption wavelengths for each polymer are given in brackets. 
The photoluminescence spectra of the polymer films are shown in Figure 5. C1 and C3 fluoresce in the green at $\approx 513$ and $490 \mathrm{~nm}$, while C2 and C6 emit at $\approx 435 \mathrm{~nm}$ when excited by a light source of $368 \mathrm{~nm}$. Thus, polymer C1 with a pyrene side chain had the largest Stokes shift of $123 \mathrm{~nm}$, followed by C3, C6, and C2. The green emission coincided with those obtained in pyrene-doped PFO structures, where the emission at $\approx 515 \mathrm{~nm}$ was directly related to the pyrene concentration of the structures [21]. Thus, the presence of pyrene in the side chain in $\mathrm{C} 1$ played a main role in the green emission observed in this work. It is noted that the spectra of C3 was rather broad, spanning from 400-700 nm. PL peaks of $\mathrm{C} 2$ and $\mathrm{C} 6$ were close to those of PFO, but the spectra were broadened as compared to the PL of PFO where the PL peaks lay at $435 \mathrm{~nm}, 464 \mathrm{~nm}$, and $493 \mathrm{~nm}$.

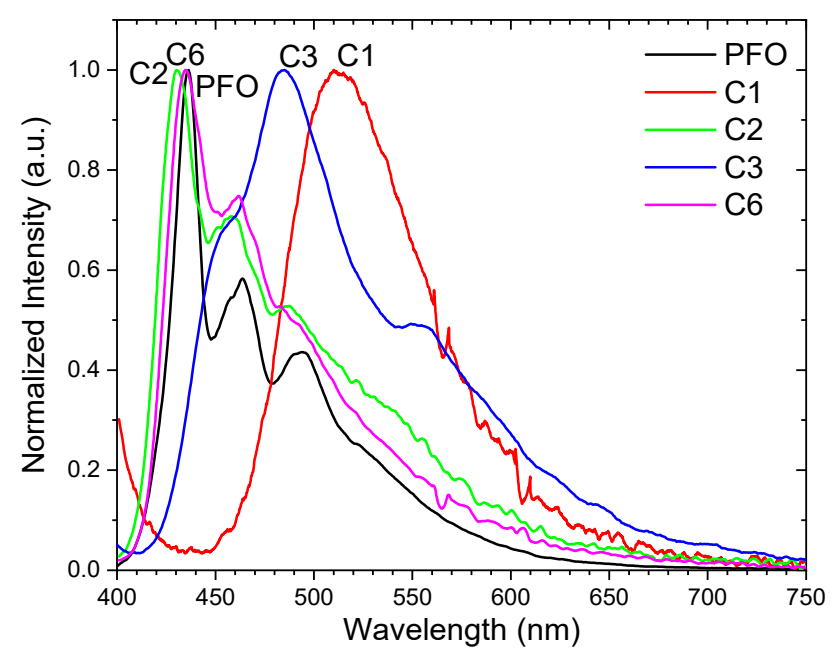

Figure 5. Normalized PL of the polymer films excited using a $368 \mathrm{~nm}$ light source.

\subsection{Electroluminescence Characteristics}

All the single-layer devices produced electroluminescence. The current-voltage characteristics of the single-layer devices of C1, C2, C3, C6, and PFO are shown in Figure 6. C1 and C3 operated at a lower voltage of $\approx 5-10 \mathrm{~V}$, while the operating voltage for $\mathrm{C} 2, \mathrm{C} 6$, and $\mathrm{PFO}$ were $\approx 10-20 \mathrm{~V}$. The emission intensity from $\mathrm{C} 1$ was the lowest among all the samples due to the lower concentration and thickness of the sample in this study. C2, C6, and PFO also exhibited higher current injections as compared to C1 and C3. The EL spectra of the devices are shown in Figure 7. The EL spectra of C1 and C3 consisted of a broad peak centered at $\approx 510 \mathrm{~nm}$ and $490 \mathrm{~nm}$, respectively, close to their PL spectra. The EL spectra from C3 spanned across the visible region from $400-700 \mathrm{~nm}$.

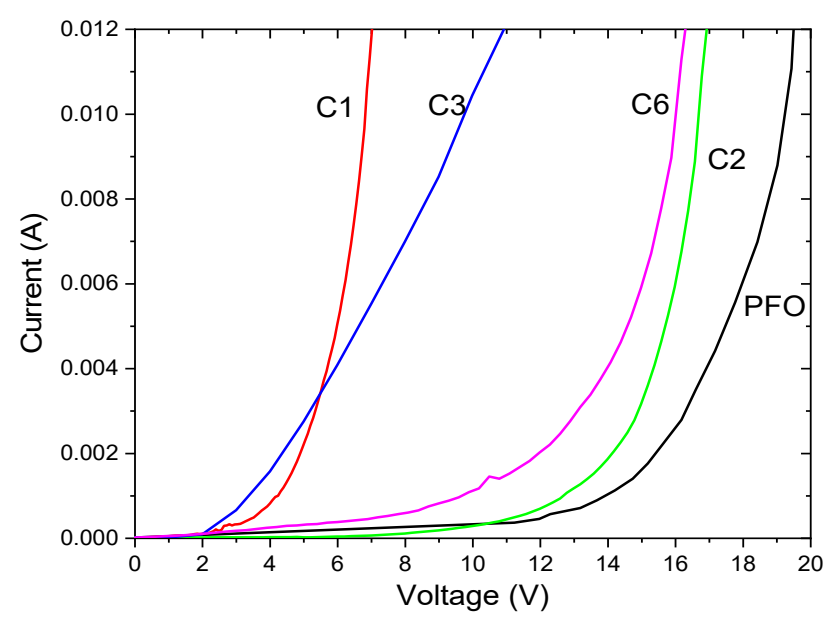

Figure 6. I-V curves for the single-layer device ITO/polymer/Al with PFO, C1, C2, C3, and C6. 

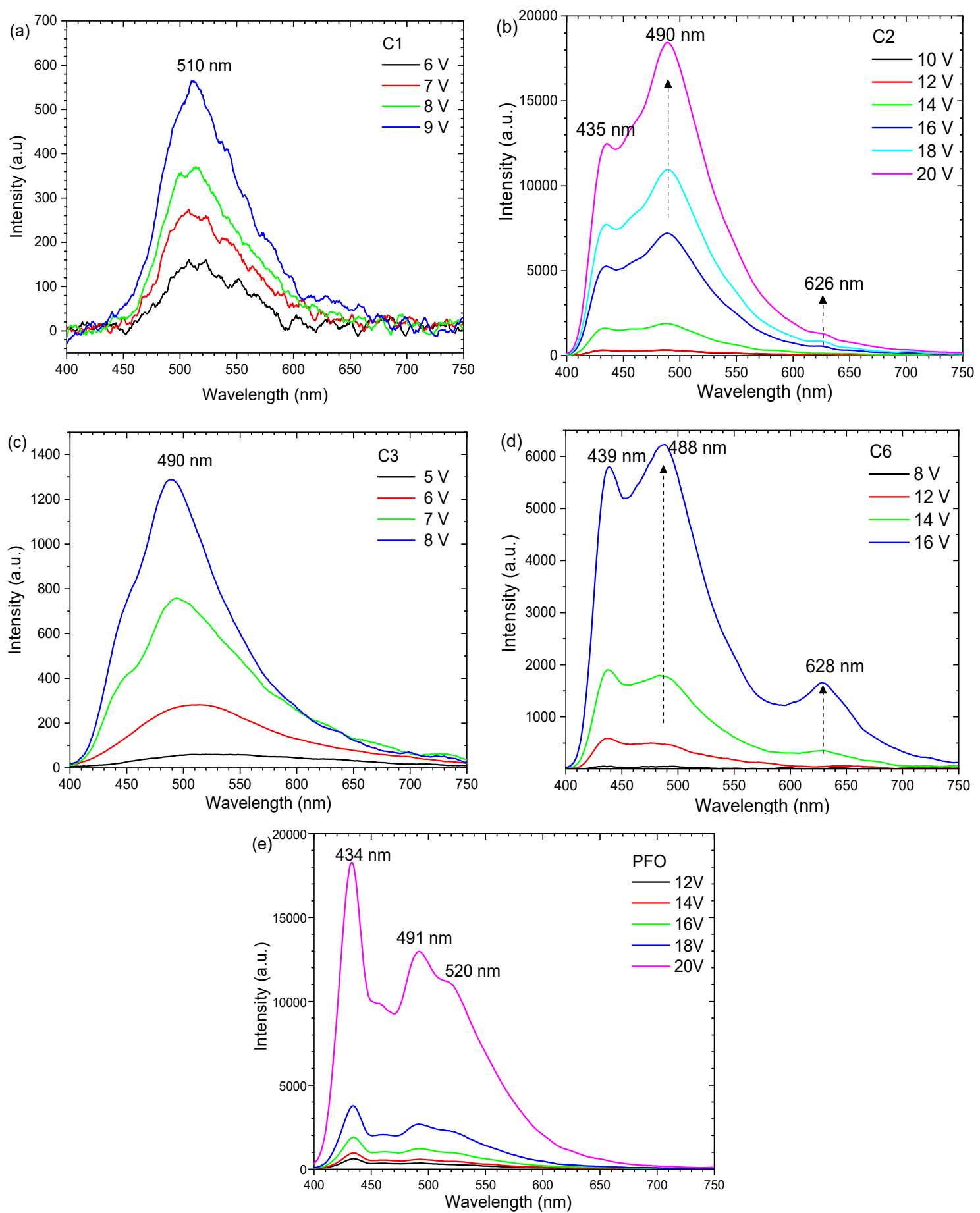

Figure 7. EL spectra of (a) C1, (b) C2, (c) C3, (d) C6 as compared to (e) PFO at different applied voltages.

Two emissions peaks were observed for both C2 and C6 at $430 \mathrm{~nm}$ and $495 \mathrm{~nm}$, while an additional peak at $520 \mathrm{~nm}$ was detected for PFO. The peak at $520 \mathrm{~nm}$ at the green emission band may be caused by oxidation effects [17]. In the report, the effects were stabilized by the presence of TPA in the polymer. The overall spectra width was broader than the PL spectra for these polymers. The intensity of PFO increased with applied voltage consistently without significant change in the spectral shape. However, for $\mathrm{C} 2$ and $\mathrm{C} 6$, the increase of the applied voltage induced changes to the spectral shape. For C2, the ratio of the intensity at $435 \mathrm{~nm}$ to $495 \mathrm{~nm}$ increased from when the voltage was increased from $10 \mathrm{~V}$ to $20 \mathrm{~V}$. Another peak at $626 \mathrm{~nm}$ emerged when the applied voltage was $18 \mathrm{~V}$. For C6, the ratio of the peak at $439 \mathrm{~nm}$ to $488 \mathrm{~nm}$ changed from 1:0.8 to 1:1.1, and another peak at $628 \mathrm{~nm}$ occurred above $14 \mathrm{~V}$. 
The devices of $\mathrm{C} 2$ and $\mathrm{C} 6$ appeared blue-white at higher voltage. The detailed spectral characteristics of each polymer are plotted in Figure S5.

\subsection{Discussion}

In order to investigate the emission spectral characteristics of the polymers, the absorbance and emission spectra of the polymers were compared to those of a PFO, as seen in Figure 8. For all the polymers, the main absorption peak of the polymers remained within 380-390 nm, unlike those that have been obtained with TPA connected through a vinylene bridge to PFO, which absorbed at $\approx 360 \mathrm{~nm}[16]$. However, as a result of peak shifting and broadening, the following observation was recorded. The spectral overlapping of the absorption and PL peak for $\mathrm{C} 1$ and $\mathrm{C} 3$ caused Forster energy transfer where PL peaks at $\approx 430 \mathrm{~nm}$ and $450 \mathrm{~nm}$ from PFO structures were absent (Figure 8a,c). The absorbance peak of $\mathrm{C} 1$ broadened and shifted, covering up to $\sim 480 \mathrm{~nm}$, thus absorbing emissions $<480 \mathrm{~nm}$ from the PFO structure. This resulted in a large Stokes shift, and PL occurred only at $515 \mathrm{~nm}$. The absorbance peak of $\mathrm{C} 3$ broadened to $\approx 450 \mathrm{~nm}$ where emission at $<450 \mathrm{~nm}$ would be re-absorbed and left with some residue emission at $450 \mathrm{~nm}$. This resulted in a PL peak at $490 \mathrm{~nm}$. The same effects were observed in another report where PFO was blended with PFM (with PFO and TPA in the backbone) [23]. In the report, deep blue emission was converted into a longer wavelength as the amount of PFM increased. C2 and C6 were less affected by the energy transfer because of less overlapping (Figure 8b,d). The higher amount of overlapping between the absorption of the polymer and the emission of a PFO structure led to a larger red shift in the order of pyrene (C1) $>$ naphthalene (C3) > isopropyl (C6) > diphenyl (C2). The larger side chain of pyrene (C1) and naphthalene (C3) induced broadening of the absorption spectra and resulted in an emission toward the green region.
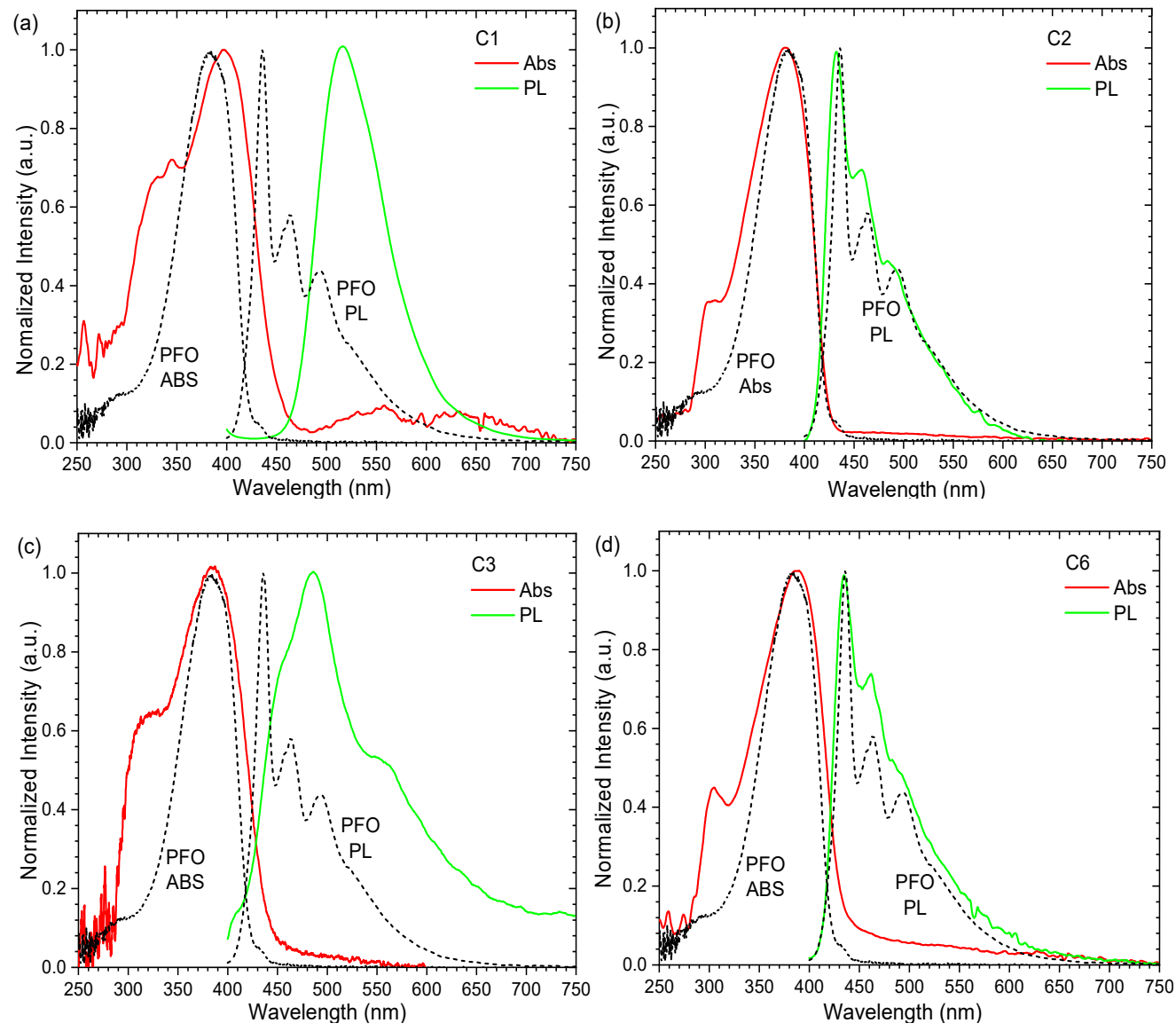

Figure 8. Absorbance and PL of the polymer films (a) C1, (b) C2, (c) C3, and (d) C6 as compared to a PFO film (black dotted line). 
At higher operation voltage, devices of a single polymer of $\mathrm{C} 2$ or $\mathrm{C} 6$ exhibited interesting EL with multiple peaks that spanned from the blue to red regions. The emission at $\approx 435 \mathrm{~nm}$ were assigned to the excitonic emission, while the peak at $490 \mathrm{~nm}$ could be due to the excimers based on the reported polyfluorene derivatives [24]. At high applied voltage, the EL spectra were different from the PL spectra due to the complex charge transport and recombination that could be involved (Figure S5). The distinct difference in PL and EL peaks has been observed in some polymers with PFO and/or TPA structures. A large red-shift in the EL peak was detected for polymers with a TPA structure (PBPITP) [25]. The PL peak was detected at $\approx 470 \mathrm{~nm}$, but EL occurred at $618 \mathrm{~nm}$, indicating a different recombination mechanism of charge carriers for PL and EL. In another report, polymers with PFO in the backbone and a TPA side chain were studied [17]. The TPA side chain was able to stabilize the blue emission from the polymer. However, a small EL peak at $630-650 \mathrm{~nm}$ was detected in the high voltage range. The origin of the additional peak in the EL spectra can be contributed by a few mechanisms. First, a keto defect can form as a result of photooxidation or thermal oxidation. However, it normally induced an additional peak at 2.2-2.3 eV (539-564 nm) for PF [26]. More importantly, TPA is electroactive where it can be excited by high applied voltage [27]. A TPA electromer or excited-state complex could be formed between molecules or subunits carrying a charge [22]. In our previous report, both C2 and C3 were shown to have fully reversible electrochromic properties [15,20]. C2 switched to green and blue, which may account for the increase of the $490 \mathrm{~nm}$ peak in Figure $7 \mathrm{~b}$. However, the red EL peak from an OLED has not been observed before. The characteristics may be related to electron removal at the $\mathrm{N}$ atom from the TPA unit in the main chain, which was observed in a polymer with only a PFO-TPA main chain (referred to as M2 in the report) [28]. When tested for its electrochromic properties, PFO-TPA thin film switches from a transmissive neutral state (pale yellow) to a fully oxidized state (red). We performed a measurement on the electrochromic properties of $\mathrm{C} 6$, the results indicated a colour transition to red upon an applied voltage of 1.2 V. Finally, the red emission may also be due to a delayed fluorescence process. The occurrence of a delayed fluorescence has been observed in amino endcapped poly[9,9-bis(2-ethylhexy1-8-luorine-2,7-diyl] where the amino consisted of TPA units. Low temperature PL measurements at $15 \mathrm{~K}$ revealed that the red emission occurred as a delayed fluorescence from triplet excitons [29]. Delayed fluorescence or phosphorescence is always red-shifted to occur at a longer wavelength. Optical excitation produce singlet excited states, while some triplet states can only be formed via intersystem crossing from the singlet excited state at room temperature. Thus, triplet luminescence can hardly be detected in PL measurements at room temperature. However, in electrical excitation, charge injection occurred to form either singlet or triplet states in addition to the intersystem crossing from singlet to triplet states [30]. Thus, the overall probability of radiative recombination to produce phosphorescence is increased in electrical excitation. Such a process requires sufficiently high carrier injection at higher operating voltage.

The EL spectra of each polymer is converted to the CIE coordinate and overlaid onto the approximate color regions on a CIE 1931 x,y chromaticity diagram (Figure 9). The emission from C1 lay within the green region, while $\mathrm{C} 3$ emitted at almost the center of the chart, and there was a shift as the voltage increased. The emissions from C2 and C6 were at the edge of the blue-violet region. $\mathrm{C} 2$ emitted in the greenish-blue region, but as the voltage increased, the resultant emission shifted when the intensity of the $490 \mathrm{~nm}$ peak increased. For the devices based on C6, the emissions in the blue-shifted towards the center region with increasing voltage at high concentration, largely due to the appearance of red emissions at $628 \mathrm{~nm}$. 


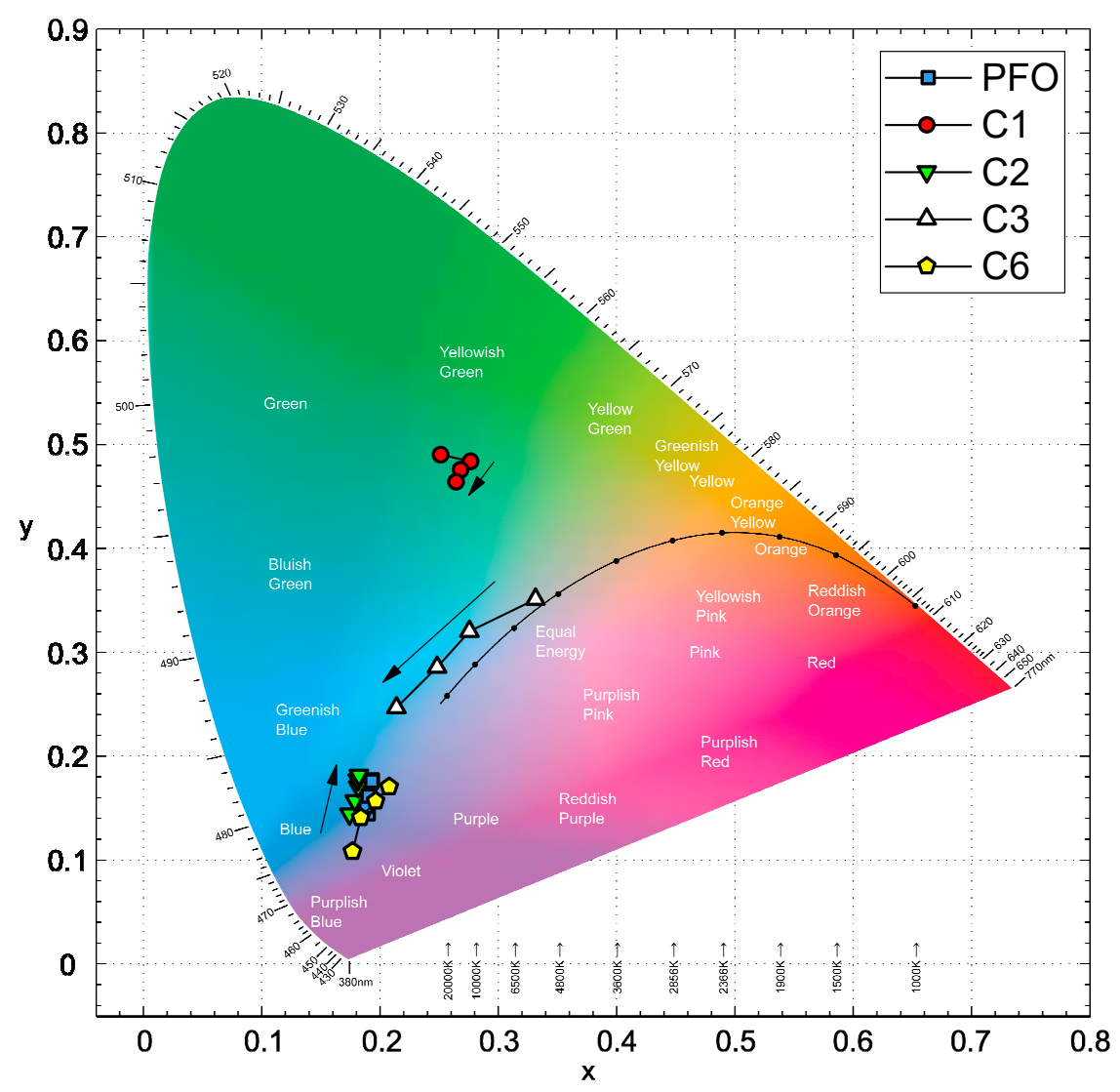

Figure 9. Chromaticity of $\mathrm{C} 1, \mathrm{C} 2, \mathrm{C} 3, \mathrm{C} 6$, and PFO devices. The increase of applied voltage (indicated by the black arrow) shifts the emission region.

\section{Conclusions}

A PF derivative with TPA exhibited interesting electroluminescence properties. Polymers with the same back bone of poly[(9,9-dioctylfluorenyl-2,7-diyl)-co-triphenylamine] with different side chains were synthesized, and their PL and EL as a single layer OLED were obtained. The different side chains greatly influenced the electroluminescence of the polymers. The polymers with a larger sidechain of pyrene (C1) and naphthalene structure (C3) suppressed the blue emission for PFO because of Forster energy transfer and resulted in a green emission. Polymer $\mathrm{C} 2$ and $\mathrm{C} 6$ exhibited multiple EL peaks at $\approx 435 \mathrm{~nm}, 490 \mathrm{~nm}$, and $625 \mathrm{~nm}$. The ratios of the peaks were dependent on the applied voltage. The results suggest tunability of the emission by varying the applied voltage. The occurrence of the red peak at $\approx 625 \mathrm{~nm}$ observed in EL but not PL spectra suggest that the recombination mechanisms are complex. The origin of the peak may be related to the electroactive nature of TPA units or from emission from triplet states, which are dependent on the applied electric field.

Supplementary Materials: The following are available online at http://www.mdpi.com/2073-4360/11/5/840/s1: Figure S1. Structure of M6 monomer, Figure S2. Structure of conjugate polymer C6, Figure S3. NMR Spectra of C6 (a) 1H NMR (b) 13C NMR, Figure S4. Cyclic voltammogram of the conjugated polymer C6 films on ITO-coated glass in acetonitrile solutions containing $0.1 \mathrm{M}$ TBAP under argon atmosphere; the scan rate was $100 \mathrm{mV} / \mathrm{s}$. $\mathrm{E}_{\mathrm{onset}}^{\mathrm{ox}}$ of $\mathrm{C} 6$ were $0.76 \mathrm{~V}$ via calculation. The $\mathrm{HOMO}$ for $\mathrm{C} 6$ was $\approx 5.16 \mathrm{eV}$. The HOMO of $\mathrm{C} 6$ was calculated using the empirical formula HOMO $=-\left(E_{\text {onset }}^{\mathrm{ox}}-E_{\text {onset }}^{\mathrm{FC}}\right)-4.8$, Figure S5. Absorbance, PL, and EL spectra of (a) C1, (b) C2, (c) C3, (d) C6, and (e) PFO.

Author Contributions: Q.Z. and P.-I.W. synthesized and characterized the polymers. G.L.O., S.H.T., Z.W.T., Y.H.H., Y.L.W., K.S.C. and T.S.O. fabricated, characterized the devices and analyzed the results. S.L.Y., T.Y.T., C.H.N., D.J.L. and S.S.Y supervised and designed the experiment. S.L.Y., C.H.N., S.S.Y and D.J.L. co-wrote the paper. 
Acknowledgments: The authors would like to thank the Ministry of Science and Technology of Taiwan (MOST) for the financial support for this work. We also acknowledge the support from Ministry of Higher Education Malaysia (MMUE 160023) and the Penang State Government (MMUE 150001).

Conflicts of Interest: The authors declare no conflict of interest.

\section{References}

1. Xie, J.; Zhao, C.E.; Lin, Z.Q.; Gu, P.Y.; Zhang, Q. Nanostructured conjugated polymers for energy-related applications beyond solar cells. Chem. Asian J. 2016, 11, 1489-1511. [CrossRef] [PubMed]

2. Wu, W.; Bazan, G.C.; Liu, B. Conjugated-polymer-amplified sensing, imaging, and therapy. Chem 2017, 2, 760-790. [CrossRef]

3. Yao, C.-J.; Zhang, H.-L.; Zhang, Q. Recent progress in thermoelectric materials based on conjugated polymers. Polymers 2019, 11, 107. [CrossRef]

4. Xie, J.; Gu, P.; Zhang, Q. Nanostructured conjugated polymers: Toward high-performance organic electrodes for rechargeable batteries. ACS Energy Lett. 2017, 2, 1985-1996. [CrossRef]

5. Morin, P.O.; Bura, T.; Leclerc, M. Realizing the full potential of conjugated polymers: Innovation in polymer synthesis. Mater. Horizons. 2016, 3, 11-20. [CrossRef]

6. Kertesz, M.; Choi, C.H.; Yang, S. Conjugated polymers and aromaticity. Chem. Rev. 2005, 105, 3448-3481. [CrossRef] [PubMed]

7. Friend, R.H.; Gymer, R.W.; Holmes, A.B.; Burroughes, J.H.; Marks, R.N.; Taliani, C.; Bradley, D.D.C.; Dos Santos, D.A.; Bredas, J.L.; Lögdlund, M.; et al. Electroluminescence in conjugated polymers. Nature 1999, 397, 121-128. [CrossRef]

8. Berggren, M.; Inganas, O.; Gustafsson, G.; Rasmusson, J.; Andersson, M.R.; Hjertberg, T.; Wennerström, O. Light-emitting-diodes with variable colors from polymer blends. Nature 1994, 372, 444-446. [CrossRef]

9. Boudreault, P.-L.T.; Leclerc, M.; Beaupré, S. Solar-energy production and energy-efficient lighting: Photovoltaic devices and white-light-emitting diodes using poly(2,7-fluorene), poly(2,7-carbazole), and poly(2,7-dibenzosilole) derivatives. Adv. Mater. 2010, 22, E6-E27. [CrossRef]

10. Yu, L.; Liu, J.; Hu, S.; He, R.; Yang, W.; Wu, H.; Peng, J.; Xia, R.; Bradley, D.D.C. Red, green, and blue light-emitting polyfluorenes containing a dibenzothiophene-S,S-dioxide unit and efficient high-color-rendering-index white-light-emitting diodes made therefrom. Adv. Funct. Mater. 2013, 23, 4366-4376. [CrossRef]

11. Liu, J.; Zhou, Q.; Cheng, Y.; Geng, Y.; Wang, L.; Ma, D.; Jing, X.B.; Wang, F.S. The first single polymer with simultaneous blue, green, and red emission for white electroluminescence. Adv. Mater. 2005, 17, 2974-2978. [CrossRef]

12. Liu, C.-F.; Jiu, Y.; Wang, J.; Yi, J.; Zhang, X.-W.; Lai, W.-Y.; Huang, W. Star-shaped single-polymer systems with simultaneous rgb emission: Design, synthesis, saturated white electroluminescence, and amplified spontaneous emission. Macromolecules 2016, 49, 2549-2558. [CrossRef]

13. Wu, F.I.; Yang, X.H.; Neher, D.; Dodda, R.; Tseng, Y.H.; Shu, C.F. Efficient white-electrophosphorescent devices based on a single polyfluorene copolymer. Adv. Funct. Mater. 2007, 17, 1085-1092. [CrossRef]

14. Lee, P.I.; Hsu, S.L.C.; Lin, P. White-light-emitting diodes from single polymer systems based on polyfluorene copolymers with quinoxaline derivatives. Macromolecules 2010, 43, 8051-8057. [CrossRef]

15. Chen, W.; Wang, K.; Hung, W.; Jiang, J.; Liaw, D.-J.; Lee, K.-R.; Lai, J.Y.; Chen, C.L. Novel triarylamine-based alternating conjugated polymer with high hole mobility: Synthesis, electro-optical, and electronic properties. J. Polym. Sci. Part A Polym. Chem. 2010, 48, 4654-4667. [CrossRef]

16. Tang, R.; Tan, Z.; Li, Y.; Xi, F. Synthesis of new conjugated polyfluorene derivatives bearing triphenylamine moiety through a vinylene bridge and their stable blue electroluminescence. Chem. Mater. 2006, 18, 1053-1061. [CrossRef]

17. Giovanella, U.; Pasini, M.; Destri, S.; Porzio, W.; Botta, C. Stabilized blue emission from polyfluorene-based light-emitting diodes: The role of triphenylamine. Synth. Met. 2008, 158, 113-119. [CrossRef]

18. Park, M.J.; Lee, J.H.; Hwang, D.H. Synthesis and light-emitting properties of new polyfluorene copolymers containing a triphenylamine based hydrazone comonomer. Curr. Appl. Phys. 2006, 6, 752-755. [CrossRef] 
19. Zhang, Q.; Tsai, C.Y.; Abidin, T.; Jiang, J.C.; Shie, W.R.; Li, L.J.; Liaw, D.J. Transmissive-to-black fast electrochromic switching from a long conjugated pendant group and a highly dispersed polymer/SWNT. Polym. Chem. 2018, 9, 619-626. [CrossRef]

20. Wu, H.Y.; Wang, K.L.; Liaw, D.J.; Lee, K.R.; Lai, J.Y. Electrochromic material containing unsymmetrical substituted N,N,N0,N0-Tetraaryl-1,4-phenylenediamine: Synthesis and their optical, electrochemical, and electrochromic properties. J. Polym. Sci. Part A Polym. Chem. 2010, 48, 1469-1476. [CrossRef]

21. Zhao, Z.; Li, J.H.; Lu, P.; Yang, Y. Fluorescent, carrier-trapping dopants for highly efficient single-layer polyfluorene LEDs. Adv. Funct. Mater. 2007, 17, 2203-2210. [CrossRef]

22. Kalinowski, J.; Giro, G.; Cocchi, M.; Fattori, V.; Di Marco, P. Unusual disparity in electroluminescence and photoluminescence spectra of vacuum-evaporated films of 1,1-bis ((di-4-tolylamino) phenyl) cyclohexane. Appl. Phys. Lett. 2000, 76, 2352-2354. [CrossRef]

23. Palilis, L.C.; Lidzey, D.G.; Redecker, M.; Inbasekaran, M.; Woo, E.P.; Wu, W.W. Bright and efficient blue and green light-emitting diodes based on conjugated polymer blends. Synth. Met. 2000, 111, 159-163. [CrossRef]

24. Bliznyuk, V.N.; Carter, S.A.; Scott, J.C.; Klärner, G.; Miller, R.D.; Miller, D.C. Electrical and photoinduced degradation of polyfluorene based films and light-emitting devices. Macromolecules 1999, 32, 361-369. [CrossRef]

25. Yu, W.-L.; Pei, J.; Huang, W.; Heeger, A.J. A novel triarylamine-based conjugated polymer and its unusual light-emitting properties. Chem. Commun. 2000, 8, 681-682. [CrossRef]

26. List, E.J.W.; Gaal, M.; Guentner, R.; De Freitas, P.S.; Scherf, U. The role of keto defect sites for the emission properties of polyfluorene-type materials. Synth. Met. 2003, 139, 759-763. [CrossRef]

27. Rybakiewicz, R.; Zagorska, M.; Pron, A. Triphenylamine-based electroactive compounds: Synthesis, properties and application to organic electronics. Chem. Pap. 2017, 71, 243-268. [CrossRef]

28. Chen, W.H.; Wang, K.L.; Liaw, D.J.; Lee, K.R.; Lai, J.Y. $N, N, N^{\prime}, N^{\prime}$-tetraphenyl-1,4-phenylenediamine-fluorene alternating conjugated polymer: Synthesis, characterization, and electrochromic application. Macromolecules 2010, 43, 2236-2243. [CrossRef]

29. Rothe, C.; Monkman, A. Triplet exciton migration in a conjugated polyfluorene. Phys. Rev. B 2003, 68, 1-11. [CrossRef]

30. Wilson, J.S.; Dhoot, A.S.; Seeley, A.J.; Khan, M.S.; Köhler, A.; Friend, R.H. Spin-dependent exciton formation in pi-conjugated compounds. Nature 2001, 413, 828-831. [CrossRef]

(C) 2019 by the authors. Licensee MDPI, Basel, Switzerland. This article is an open access article distributed under the terms and conditions of the Creative Commons Attribution (CC BY) license (http://creativecommons.org/licenses/by/4.0/). 